\title{
Putting sustainability into Sustainable Human Development
}

Peeters, Wouter; Dirix, Jo \& Sterckx, Sigrid

[Chapter in Lessman, O. \& Rauschmayer, F. (Eds), The Capability Approach and Sustainable Development. New York: Routledge, pp. 57-75.]

\begin{abstract}
Abating the threat climate change poses to the lives of future people clearly challenges our development models. The 2011 Human Development Report rightly focuses on the integral links between sustainability and equity. However, the Human Development and Capabilities Approach emphasizes the expansion of people's capabilities simpliciter, which is questionable in view of environmental sustainability. We argue that capabilities should be defined as triadic relations between an agent, constraints and possible functionings. This triadic syntax particularly applies to climate change: since people's lives and capabilities are dependent on the environment, Sustainable Human Development should also include constraining human activities in order to prevent losses in future people's well-being due to the adverse effects of exacerbated climate change. On this basis, we will advocate that the goals of Sustainable Human Development should be informed by a framework that consists in enhancing capabilities up to a threshold level, as well as constraining the functionings beyond this threshold in terms of their GHG emissions.
\end{abstract}

\section{Key words:}

Sustainable Human Development, 2011 HDR, capabilities, climate change

\section{Introduction}

Neumayer notes that the literatures on human development and sustainable development have long been separate, which is surprising because 'on a very fundamental level, human 
development is what sustainability proponents want to sustain and without sustainability, human development is not true human development' (2010, p. 1). This has changed with the introduction of the Human Development Reports (HDR) by the United Nations Development Programme (UNDP). The concept of Sustainable Human Development (SHD) gained real prominence in the $1994 \mathrm{HDR}$, which argued that there is no tension between human development and sustainability, because both are essential components of the universality of life claims, which 'is the common thread that binds the demands of human development today with the exigencies of development tomorrow' (p. 13). The 2007/8 HDR argues that climate change affects all people in all countries, but the world's poorest are the most vulnerable to its harmful effects (p. 21). Together with the history of emissions accumulation and distribution, this points to an inverse relationship between climate change vulnerability and responsibility (p. 43). The 2010 HDR reiterates the centrality of ethical universalism, arguing that SHD is about making sure that present as well as future people can lead healthy, educated and fulfilling lives: 'human development, if not sustainable, is not true human development' (p. 19). The latest (2011) HDR highlights the integral links between the closely related challenges of environmental sustainability and equity (p. 13).

Environmental sustainability relates to 'the need to operate within the ecological carrying capacity of the earth' (Ross 2009, p. 38). In order to avoid unacceptable environmental change and maintain the biophysical preconditions for human development, human activities should not transgress certain 'planetary boundaries' (Rockström et al. 2009, p. 472). ${ }^{1}$ Hence, environmental sustainability should be at the core of SHD - which is acknowledged by the 2011 HDR (p. 16). Thus, the social goal of enhancing people's capabilities and well-being should be situated within the biophysical constraints of the ecosphere.

Although it is not the only environmental threat, we focus on climate change for two important reasons. First, 'climate change represents one of the most serious and far-reaching challenges facing humankind in the twenty-first Century,' because the economic, social, human and environmental costs of inaction are likely to be extremely high (Byers et al. 2005, p. 1). Hence, climate change mitigation should be regarded as a central concern of SHD. ${ }^{2}$ Keeping the most likely global warming due to greenhouse gas (GHG) emissions to $2^{\circ} \mathrm{C}$ above pre-industrial levels will require us to limit cumulative GHG emissions over the entire "anthropocene" (Allen et al. 2009, p. 56). The adverse effects of unmitigated human-induced climate change thus clearly illustrate the need for taking the biophysical constraints of the ecosphere seriously - in this case, the maximum permissible budget of total net GHG emissions. ${ }^{3}$ Second, GHG emission rates continue to increase with a rising Human 
Development Index (HDI) (UNDP 2011, p. 30). Although the resulting environmental cost is mainly attributable to economic growth, it is clear that the efforts needed to mitigate climate change challenge our development models.

We welcome the focus of the 2011 HDR on the links between sustainability and equity. However, the question addressed in this paper is whether the account developed by the 2011 HDR - and more broadly, by the Human Development and Capabilities Approach (HDC approach $)^{4}-$ meets these requirements of environmental sustainability. We will argue that the HDC approach cannot adequately scrutinize the share of material progress in its model of development, due to some ambiguities in its theoretical underpinnings. Subsequently, we will argue that capabilities need to be conceptualized as triadic relations between an agent, constraints and possible functionings. Building on recent debates in the literature, we suggest that this triadic syntax demonstrates that there is a strong moral reason to constrain human activities in order to prevent losses in future people's well-being due to the aggravated adverse effects of unmitigated climate change. In section four we will therefore advocate that the goals of SHD should include the expansion of people's freedoms and capabilities up to a threshold level, as well as constraining people's functioning combinations in terms of their GHG emissions.

\section{The 2011 HDR: integral links between equity and sustainability}

The 2011 HDR sets out by stating that the past progress rates of human development might not continue because conditions regarding the two key dimensions of environmental sustainability and equity have deteriorated (p. 13). Therefore, the main issues are 'the adverse repercussions for human development of the lack of environmental sustainability ... and more positively, the intersections between greater sustainability and equity, as well as the potential for progressive reforms that promote both goals' (p. 19). Considering equity and sustainability jointly does not mean that they are mutually reinforcing in all instances, but compels us to identify positive synergies between the two and to give special consideration to the trade-offs.

This account is explicitly based on the universality of life claims, 'the recognition of a shared claim to the basic capability to lead worthwhile lives' (Anand \& Sen 1994, p. 4). While the uncertainty about future people's capabilities led earlier positions (e.g. Anand \& Sen 1994, pp. 27-28; UNDP 1994, p. 18) to assume the feasibility of the substitutability of environmental by human capital, the 2011 HDR by contrast argues that this uncertainty 
requires protecting the availability and diversity of natural resources (p. 14). In view of the detrimental impacts of anthropogenic climate change, the 2011 HDR forcefully states that 'the message is clear: our development model is bumping up against concrete limits' (p. 15).

We endorse the 2011 HDR's emphasis on the integral links between equity and sustainability, as well as its concerns regarding climate change within the framework of ethical universalism. Nonetheless, some ambiguities remain in its account of SHD. The 2011 HDR criticizes sustainability perspectives, noting that, in general, they do not adequately capture SHD: "they do not refer to the expansion of choice, freedoms and capabilities intrinsic to human development' (p. 17). Many of these accounts allegedly view equity and the plight to the poor as separate and unrelated issues (p. 19). While this critique is to a certain extent valid, the pendulum should not swing too far the other way: an account of SHD must also avoid the risk of overemphasizing human development at the cost of sustainability.

Consider the HDC approach's treatment of the income dimension. On the one hand, it heavily criticizes the opulence-oriented view of development for being an insufficient basis for human development: freedom also depends on other determinants - such as social arrangements and political and civil liberties (Sen 1999, p. 3; UNDP 2010, p. 40). The HDC approach substantiates its model of development accordingly, incorporating health and education together with income. Moreover, the 2011 HDR criticizes economic growth, because income inequality has worsened and the environmental cost of climate change is positively associated with income growth (p. 25). These observations are consistent with the substantial arguments in the literature on the limits to growth (e.g. Jackson 2009; Meadows et al. 1972).

The question as to whether present lifestyles are acceptable was already raised in the 1994 HDR, which claims that 'a major restructuring of the world's income and consumption patterns may be a necessary precondition for any viable strategy of sustainable development' (p. 19). The HDR 1998 similarly states that the environmentally damaging consumption of some harms the well-being of others (p. 47). Indeed, the HDR 2011 scrutinizes consumption patterns in the very high HDI countries: today's atmospheric GHG concentrations are largely the accumulation of developed countries' past emissions, and people in very high HDI countries still account for many times the emissions of people in the least developed countries (UNDP 2011, pp. 32-33).

On the other hand, however, the HDC approach also acknowledges the instrumental value of income: income growth can be 'very important as [a] means to expanding the freedoms enjoyed by the members of the society' (Sen 1999, p. 3, emphasis in original). The HDI 
includes the income dimension as a proxy for a decent standard of living, as a surrogate for all human choices that are not reflected in the health and education dimensions (UNDP 2000, p. 17). The importance of the income dimension is nuanced in the current computation by taking the geometrical average of the HDI's three dimensions to limit substitutability between them, and by using the natural logarithmic adjustment of real income per capita in order to reflect the assumption that the transformation of income into well-being diminishes with increasing income (UNDP 2010, p. 216). Yet this methodology retains economic growth as a prominent indicator of a country's development, even when the observed income level rises above what might be called a decent standard of living. Indeed, the 2010 HDR admits that 'countries became top performers on the HDI through two broad routes: fast income growth or exceptional progress in health and education' (p. 46). Despite the critical considerations mentioned above, the development and material wealth levels of these top performers remain the normative goal of development. "Very High Human Development" appears to take precedence over its consequences, including sustainability (Crabtree, this issue).

Including economic growth unqualifiedly as an intrinsic part of the development model is morally questionable in view of the requirements of environmental sustainability. Given the biophysical constraints of the ecosphere, the development model and GHG emission levels of the very high HDI countries cannot be transferred to the rest of the world (Sachs \& Santarius 2007, p. 151). Nonetheless, developing countries' development is structured to follow their unsustainable path: emissions in the developing countries have doubled in the last two decades, accounting for most of the global emissions growth (Peters et al. 2011, p. 8903). Climate change thus challenges the definition of human development as the expansion of people's substantive freedoms, when the latter are conceptualized simpliciter and presuppose the possibility of infinite material progress.

The 2011 HDR distinguishes between three categories of environmental risk factors (p. 27). First, risks with an immediate impact on households (e.g. poor water quality and sanitation) decline as the HDI rises. Second, risks with community effects (e.g. urban air pollution) follow the Environmental Kuznets Curve: they first worsen as the HDI rises and later improve. Finally and in contrast, environmental risk factors with global effects (e.g. GHG emissions) continue to increase with a rising HDI. Hence, in the case of climate change, calling for more human development in the form of the expansion of freedoms simpliciter is insufficient to abate the threat. Nonetheless, Anand and Sen insist that human development is not only intrinsically important in enhancing current people's capabilities, but also instrumentally important "in increasing their "human capital" with lasting influence in the 
future' (1994, pp. 32-33). Hence, they consider human development to be a major contribution to sustainability. Essentially following this reasoning, the 2011 HDR for example supports community management of environmental resources as an alternative to centralized control (p. 75). Although such initiatives represent needed synergies between equity and sustainability, in view of the adverse effects of global environmental threats - such as climate change - on the living conditions of especially future people (see section 3 below), there is also a strong moral reason to constrain the appropriative material demands on the global environment, especially by the worldwide consumption elites (Sachs \& Santarius 2007, p. 153). However, the 2011 HDR still does not include environmental sustainability in the calculations of the HDI, ${ }^{5}$ although the HDI is exactly the headline indicator, 'the figure that impacts most on those that read each HDR, and especially so given the presentation of the results as a league table of attainment' (Morse 2003, p. 192). "Greening" the HDI would provide a more nuanced account of human development and have a greater impact on development policies (see for example Morse 2003; Neumayer 2010).

The 2011 HDR defines SHD as 'the expansion of the substantive freedoms of people today while making reasonable efforts to avoid seriously compromising those of future generations' (p. 18). This definition is normative: only the sustainability of states of events that expand substantive freedoms is sought for. For example, regarding energy policy, the 2011 HDR argues that 'equitable and sustainable development requires making energy available for all, controlling emissions and shifting to new and cleaner energy sources' (p. 67). As much as this is true, problems arise when the 2011 HDR focuses on "greening" the production of energy and devalues measures to reduce energy consumption (e.g. price incentives; pp. 67-70, see especially table 4.1). Hence, it clearly favours efficiency measures at the production side because they do not conflict with the expansion of freedoms, while reducing energy consumption potentially restricts individual freedoms.

However, a sensible strategy to tackle climate change must address both aspects. A onesided focus on production efficiency is flawed, because decoupling - lowering the carbon intensity of production - is a vital, but far from convincing strategy to achieve sustainability: improvements in production efficiency have been negated by total consumption growth, resulting in a continued increase of GHG emissions (Jackson 2009, p. 67; Mont \& Plepys 2008, p. 531; Ross 2009, pp. 35, 51). Moreover, there is a growth in GHG emission transfers via international trade, which partially explains the stabilization of emission rates in the developed countries and the steep increase in developing countries (Peters et al. 2011, p. 8903). Reducing patterns and levels of material consumption in the developed countries is a 
vital strategy for attaining sustainability, but the clash between these distributional issues and consumer sovereignty principles (Mont \& Plepys 2008, p. 531; UNDP 1998, p. 86) explains the reluctance of the HDC approach to thoroughly scrutinize luxury consumption.

In our view, these ambiguities are a logical consequence of a theoretical framework that identifies human development with the expansion of people's freedoms simpliciter. According to Sen, human development reasoning and the social choice theory at its basis are "firmly tied to asking "comparative" questions: how can we advance justice or reduce injustice in the world?' (2008, p. 337). In contrast with Rawls's transcendental approach which focuses on the identification of fully just institutions - Sen argues that we should concentrate on ranking alternative social arrangements (2006, p. 216; 2009, pp. 101-102). Advancing justice or reducing manifest injustices in a society, 'demands comparative judgments about justice, for which the identification of fully just social arrangements is neither necessary nor sufficient' (2006, p. 217). Although we are sympathetic to Sen's concerns, this approach at least gives the impression that the expansion of freedoms simpliciter - could proceed ad libitum (Crabtree 2010, p. 163) and lacks an account of justifiable restrictions on freedom (see below). Indeed, the 1990 HDR argues that human development is a process of enlarging people's choices that in principle 'can be infinite and change over time' (p. 10, box 1.1, emphasis added). This conception is particularly questionable in view of the risk that freedoms are used for unsustainable actions (Rauschmayer et al. 2011, p. 13). Indeed, 'some freedoms and lifestyles (not least those reliant on carbon based growth) that many people may value ... can have detrimental consequences for present and coming generations' (Crabtree 2010, p. 163).

This is not to say that the HDC approach underestimates the challenges that climate change poses to our development models or depreciates the requirements of sustainability. Our claim here is that these challenges should figure more explicitly: the HDC approach would benefit from unambiguously rejecting the view of capabilities as 'a set of disembodied freedoms' (Jackson 2009, p. 45). To be clear, we do not wish to deny people the right to a decent standard of living; SHD can ignore neither the inequitable deprivation in the developing countries, nor the unsustainable consumption levels in the developed countries. We do not reject the moral imperative of expanding human freedoms, but SHD should explicitly acknowledge the biophysical constraints of the ecosphere. That is, a high quality of life ought to be ensured while sustaining the carrying capacity of the ecosphere through respecting its biophysical constraints.

In the following section, we will therefore draw on the existing literature to advocate 
viewing capabilities within a triadic syntax, for this not only draws attention to the expansion of people's capabilities, but also to the necessity of constraining human activities in order to prevent people's actions from causing illegitimate harm to others. The triadic syntax particularly applies to climate change: since people's lives and capabilities are dependent on the environment, SHD should include constraining human activities in order to prevent losses in future people's well-being due to the aggravated adverse effects of exacerbated climate change. On this basis, section four of this paper will sketch a framework that consists in enhancing capabilities up to a threshold level, while constraining the functionings beyond this threshold.

\title{
3. Capabilities and environmental dependency
}

\subsection{Capabilities as triadic relations}

MacCallum rejects the canonical distinction between negative and positive freedom - most vividly described by Berlin (1969, pp. 121-122) - in favour of a triadic conceptualization:

\begin{abstract}
Whenever the freedom of some agent or agents is in question, it is always freedom from some constraint or restriction on, interference with, or barrier to doing, not doing, becoming, or not becoming something. Such freedom is thus always of something (an agent or agents), from something, to do, not do, become, or not become something; it is a triadic relation (1967, p. 314, emphasis in original, footnote omitted).
\end{abstract}

Arguably, this triadic syntax is implicitly acknowledged by the HDC approach. For example, even though Sen has primarily focused on capability sets - which has 'the effect of taking note of the positive freedoms in a general sense (the freedom "to do this," or "to be that") that a person has' (1985, p. 201) - he also recognizes both the instrumental and intrinsic importance of negative freedoms (1985, p. 219; 1988, p. 275). Hence, capabilities can be understood as an agent $x$, who is free from constraint $y$ to achieve functioning $z$.

The HDC approach clearly illustrates that constraints to freedom can arise from numerous sources (such as disability, illness, social conditions and institutional arrangements), but the 
notion of freedom particularly draws attention to cases where the presence of an obstacle can be attributed to the action of another human being (Miller 1983, p. 68). Indeed, people's choices are deeply interconnected and can have important consequences upon other people's lives, including the barriers $x_{2}$ 's actions can impose to the capabilities of $x_{1}$, and which may lead to losses in the well-being of $x_{1}$ (Deneulin 2002, p. 507).

Hence, considering capabilities within the triadic syntax not only brings the freedom from constraints to the foreground, but also includes the necessity of constraining people's freedom in order to prevent illegitimate interference that reduces another person's well-being. Deneulin argues that a capability theorist who emphasizes the crucial role of freedom as a component of human well-being should recognize policy interventions that restrain individual freedoms for the greatest well-being of all (2002, p. 507). In the liberal political tradition, such form of paternalistic intervention can be justified with reference to Mill's harm principle (Deneulin 2002, p. 510, Nussbaum 2000, p. 53) - that is, 'the only purpose for which power can be rightfully exercised over any member of a civilized community, against his will, is to prevent harm to others' (Mill, 2008, p. 14).

In sum, whereas the HDC approach can lead to conceptualizing human development as expanding freedoms infinitely, viewing capabilities within the triadic syntax entails that the imperative of enhancing people's capabilities also includes policy interventions that impose certain constraints, in order to prevent their actions from causing harm to others and, thus, consists in carefully balancing freedoms and constraints. In the following subsection, this triadic syntax will be applied to the issue of climate change and our commitments to future people.

\subsection{Environmental dependency and commitments towards future people}

The HDC approach recognizes that the quality of the natural environment and the health of ecosystems are crucial for allowing people to lead the lives that they value (Sen 2010, p. 130; this issue; Nussbaum 2011, p. 163; UNDP 2011, p. 14; Hirvilammi et al., this issue). To take account of this instrumental value of nature to human life, Holland has proposed to add “"Sustainable Ecological Capacity" as a meta-capability,' which involves the ability to live in the context of ecological conditions that can provide environmental assets that enable people's capabilities, now and in the future (2008a, p. 324). On this basis, she develops an environmental justice threshold - in addition to Nussbaum's threshold of social justice (see below) - which represents a level at which ecological systems have the capacity that enables 
them to provide the assets necessary to reach the threshold of social justice (p. 328). As long as ecosystems have this capacity, the ecological conditions of justice are met.

Since people's capabilities and well-being are dependent on the environment, climate change clearly violates the universality of life claims to the capabilities necessary to live a worthwhile life. Obviously, the freedom from the adverse effects caused by exacerbated anthropogenic climate change is central to reaching the environmental justice threshold. ${ }^{6}$ Indeed, unmitigated climate change is projected to result in inter alia increasing the return period and severity of extreme climate events (such as floods, droughts, and heatwaves), reduced water and food security, increased health risks, ecosystem degradation and mass migration (Costello et al. 2009, pp. 1698-1699; UNDP 2007, pp. 27, 30). These adverse effects are likely to prevent future people from achieving the environmental justice threshold and thus, to threaten their lives and capabilities (including health, shelter and nourishment).

Expressed in the triadic syntax, the universality of life claims at least requires that future people $(x)$ are free from constraints imposed by the adverse effects of exacerbated anthropogenic climate change $(y)$ to be able to live a worthwhile life $(z)$. Although the identities of future individuals are not yet determined and thus not knowable, as humans they will all be entitled to human rights and capabilities (Shue 2011, p. 293). Due to exacerbated climate change, they will be even less able to reach the environmental justice threshold, which is preconditional for social justice. Byers et al. argue that 'preventing dangerous climate change, therefore, must be seen as a precondition for prosperity and a public good' $(2005$, p. $1)$.

Sen generally acknowledges that capabilities entail responsibilities and duties of others (2009, p. 372) and the 2010 HDR recognizes that the reality of climate change requires a fundamental reshaping of people's behaviours and aspirations. However, the 2010 HDR (p. 21) and Nussbaum (2011, pp. 163-164) admit that the issue of our commitment towards future people remains a challenge that has yet to be tackled by the HDC approach. Indeed, the assumption of sustainability that 'the current generation might have to restrict itself in some ways (e.g. restrict its consumption) in order to ensure the preservation of the opportunity for a full life for future generations' has not yet been given profound theoretical consideration in the HDC approach (Leßmann 2011, p. 50).

Consistent with environmental sustainability, SHD thus also includes the necessity of constraining human activities in order to prevent illegitimate harms and losses in future people's well-being due to exacerbated climate change. Therefore, in the following section, 
we will advocate that the goals of SHD should be constructed in accordance with a framework consisting of capability thresholds and functioning constraints.

\section{Thresholds and constraints in view of sustainability}

As argued earlier, the comparative approach of Sen and the human development paradigm might lead to identifying human development with expanding people's freedoms unrestrictedly, which is problematic in view of environmental sustainability. Yet, the goals of SHD should be constructed both in accordance with an idea of what social justice consists of and the requirements of environmental sustainability in view of intertemporal justice.

\subsection{Capability thresholds}

Based on the Aristotelian idea of truly human functioning and informed by the idea of a life with human dignity, Nussbaum has introduced the idea of a threshold level of each capability 'beneath which it is held that truly human functioning is not available to citizens; the social goal should be understood in terms of getting citizens above this capability threshold' (2006, p. 71). This minimum account of social justice goes beyond Sen's 'merely comparative use of the capability space to articulate an account of how capabilities, together with the idea of a threshold level of capabilities, can provide a basis for central constitutional principles that citizens have a right to demand from their governments' (2000, p. 12). Although it is an incomplete account of justice (see below), Nussbaum's approach offers a more tangible basis than the comparative approach for the construction of the social goals that should figure in SHD: 'the structure of social and political institutions should be chosen, at least in part, with a view to promoting at least a threshold level of these human capabilities' (Nussbaum 2000, p. 75). Nussbaum distinguishes between capabilities closely related with the idea of human dignity, and instrumental capabilities (2006, pp. 292-293). While human dignity requires the equal protection of dignity-securing capabilities (such as political and religious freedoms) for everyone, in the case of instrumental capabilities (for example, shelter and nutrition), in contrast, 'what seems appropriate is enough' (2006, p. 293, emphasis in original). Although we would rather make the differentiation within capabilities - that is, each capability requires that the corresponding social as well as material conditions are satisfied - we agree that in order for people to reach a capability threshold, social conditions should be secured equally, while material conditions should be provided sufficiently (see also Peeters 2011, p. 18-19). 
GHG emissions obviously fall on the side of material conditions; hence, it seems that they should be distributed sufficiently in order to guarantee the capability thresholds. In this regard, Shue has argued that a moral differentiation should be made between subsistence (or survival) and luxury emissions (1993, p. 56). This account has been developed further by Vanderheiden, whose modified equal shares model starts from the claim that 'all persons are entitled as a matter of basic rights to survival emissions, or a level of emissions sufficient to allow for their basic human functioning' (2008, p. 243).

However, Gardiner rightly claims that if some emissions are deemed morally essential, then they may have to be guaranteed even if this leads to an overall allocation above the scientific optimum (2004, p. 585). Moreover, determining what counts as guaranteed minimum emission entitlements (or, in our view, the threshold levels on capabilities) is a difficult matter, both in theory and in practice (2004, p. 585). This also seems procedurally odd, for proposals for an unequal - sufficientarian - distribution of emission entitlements appear 'to envisage that the climate change problem can be resolved by appealing to some notion of social necessity that is independent of, and not open to, moral assessment' (p. 586). Furthermore, both the "subsistence emissions" proposal and the idea of capability thresholds carry the political risk that there is nothing to stop some people claiming that almost any emission is essential to their way of life. Finally, it is hard to see how any agreement could be reached on minimum emission entitlements that does anything less than exhaust the maximum permissible on climatological or intertemporal grounds.

The account of minimal social justice that takes capability thresholds as its point of departure addresses these problems somewhat better. First, it is important to note that GHG emissions merely represent the means in pursuing the goals that people value: 'carbon emissions should not be the object of a human right because a decent human life does not inherently depend on them' (Hayward 2007, p. 440). Rather than emphasizing the right to a certain amount of emissions, each person is entitled to the capabilities up to a certain threshold level, which does not hold that they are entitled to the supply of a specific amount of particular resources. Moreover, the equal per capita proposal to distribute emission entitlements fails to take account of the fact that emissions may play very different roles in people's lives (Gardiner, 2004, p. 584). Since the conversion of resources into the ability to promote particular ends may vary from person to person, equality in the holdings of resources can lead to serious inequalities in actual freedoms (Sen 1990, p. 115). The idea of capability thresholds emphasizes that material conditions should be provided sufficiently in order to 
enable people to lead a worthwhile life, and thus takes these interpersonal variations into account.

Second, obviously much depends on how the capability thresholds are defined. Nussbaum contends that the precise determination of the thresholds is a matter for democratic debate in each nation, but that we should avoid specifying unrealistically high thresholds as well as setting the thresholds lower than human dignity seems to require (2006, p. 402; 2011, pp. 4142). These debates should be inextricably connected to the fundamental moral questions climate change poses concerning how we ought to live, what kinds of societies we want, and how we should relate to the natural environment (Jamieson 1992, p. 147). Hence, the notion of social necessity inherent in the idea of capacity thresholds - and people's claims to emissions - must be critically assessed in view of the scarcity of permissible GHG emissions. In our view, these suggestions must guide the determination process of the precise thresholds, which admittedly remains an issue that requires much deeper consideration.

Third, the idea of "subsistence emissions" relates to the historical specificity of political and economic conditions: the lack of affordable and sustainable alternative energy still renders many or even most people dependent on fossil fuels for their subsistence (Hayward 2007, pp. 440-441; Shue 2011, p. 307). However, as noted above, the focus on capability thresholds shows the merely instrumental value of GHG emissions. As long as people are locked in a situation of carbon-dependency, they should be allowed to emit the GHGs necessary to reach the threshold level. Obviously, however, the requirements of environmental sustainability call for the urgent development and supply of affordable alternative technologies, which enable people to reach the threshold level with significantly less GHG emissions. Shifting the focus to capability thresholds thus acknowledges the fact that people have differential access to energy sources. In sum, individuals have valid claims to emit the GHGs that are necessary for reaching the capability thresholds, therefore the collective goal of SHD should be to secure the capability thresholds for every person in an ecologically optimal way, appropriating as little as possible of the total permissible GHG budget.

\subsection{Functioning constraints}

Nonetheless, the threshold framework does not deliver a complete account of justice, since it says nothing about capabilities and functionings above the thresholds (Nussbaum, 2006, p. 75). Opportunities are likely to result in corresponding functionings beyond the threshold and 
these might be unsustainable. However, people are able to control (to some extent, at least) their emissions (Vanderheiden 2008, p. 178) - in particular those that are not necessary for reaching the threshold - and the lifestyles of individuals clearly matter in the realization of sustainability (Spillemaekers et al. 2011, p. 79).

Since Nussbaum's account does not specify a way to regulate people's activities beyond the threshold, another mechanism should be applied in order to address this individual responsibility for climate change mitigation. That is, SHD should also include policy interventions that constrain people's activities beyond the threshold in terms of their fair share of the maximum permissible GHG budget in order to prevent losses in future people's wellbeing due to exacerbated climate change.

Therefore, consistent with the HDC approach's emphasis on capabilities, some have proposed to constrain people's capabilities as a strategy for achieving sustainability. For example, Jackson argues that the concept of capabilities should be carefully interpreted 'as a range of "bounded capabilities" to live well - within certain clearly defined limits' (p. 45). More elaborately, Holland has proposed the idea of capability ceilings that establish maximum levels of capability protection (2008b, p. 416). The purpose of capability ceilings, she asserts, is 'to limit the amount of resources that can be put to protecting capabilities that are in conflict with each other' (p. 416).

While our view is clearly informed by these proposals to restrict freedom, we would advocate that the focus be shifted to functioning constraints. For, putting ceilings on capability protection seems counter-intuitive in light of what a capability represents, viz. 'the substantive freedom to achieve alternative functioning combinations (or, less formally put, the freedom to achieve various lifestyles)' (Sen 1999, p. 75). Moreover, Nussbaum argues that the threshold of each capability should be set in view of the other capabilities (2006, p. 402), thus implying that settling conflicts in the protection of different capabilities is an essential part of the determination of the thresholds. Furthermore, since the thresholds require that material conditions be provided merely sufficiently, the amount of resources that is allocated to capability protection is already limited to what is deemed appropriate or sufficient for a life with human dignity. Beyond the threshold, though, it is not merely having a capability, but the functionings derived from it that potentially causes harm, through the impact these functionings have on the natural environment (Peeters 2011; Schultz et al., this issue). Therefore, it seems more accurate to reformulate capability ceilings in terms of functioning constraints that restrain people from functioning in a way that would impose illegitimate barriers to other people's lives and capabilities. This reformulation makes the discrepancy 
between people's entitlements to capabilities and the necessity of preventing them from illegitimately and harmfully interfering with other people's lives theoretically transparent. Moreover, this focus on functionings can take account of the total life cycle of resource use needed for realizing well-being (Schultz et al., this issue).

A policy that implements functioning constraints admittedly reduces the freedom of choice and, hence, restricts the capability space as well. That is, 'some functionings may even be forestalled completely, particularly where they rely heavily on material throughput' (Jackson 2009, p. 47), which evidently also excludes the capabilities to achieve those functionings from people's capability set. Yet, in the case of other functionings, the material throughput may be less heavy and to the extent that GHG emitting activities are ubiquitous in people's lives, it is hard to focus on specific activities. In our view, it seems appropriate to constrain an individual's aggregate net appropriation of the maximum permissible GHG budget. Although it reduces the freedom of choice as well, constraining people's functioning combinations as a whole notably respects agency freedom. That is, people retain the freedom as well as the responsibility of managing their limited environmental resource budget according to their priorities and their particular conception of the good life. Within the confines of a limited GHG emissions budget, a person might for example decide to no longer undertake city trips by plane in order to eat some meat - although the climatic equivalence of these activities must clearly be decided on the basis of a scientific account. Moreover, it is clear that, for example, energy-consuming activities beyond the threshold might be more permissible the more they are powered by non-fossil energy.

In our view, distributing the GHG emissions budget that remains after securing the threshold on an equal per capita basis seems to be the most obvious and equitable solution. As mentioned above, it may be objected that an egalitarian distribution does not take account of the interpersonal variations that govern the conversion of resources into ends. However, the provision of sufficient material conditions so as to enable everyone to reach the capability thresholds partly accommodates for interpersonal variations. Moreover, it might be questioned whether justice requires taking the interpersonal variations into account even beyond the threshold - concerning the attainment of luxury.

A policy that implements functioning constraints seems appealing because it focuses on the demand side and hence, would reduce total consumption - which is the most important strategy for achieving sustainability (see above). It can also be instrumental in attaining consumption efficiency (lowering the carbon intensity of products) since under such a policy producers would have to "green" their production processes in order to remain competitive. 
Both strategies are vital to mitigate climate change and thus for protecting future people. Unfortunately, sustainability strategies are often (perceived as) an obstacle to freedom (Rauschmayer et al. 2011, p. 13). Functioning constraints indeed at first appear to contradict the moral imperative of expanding people's freedoms. However, constraining people's materialist consumption beyond what is necessary for reaching the capability thresholds is likely to improve their capabilities, for example through enhancing their freedom from the barriers imposed by the damaging social logic of materialism and consumerism (such as consumer anxiety, work stress and lack of time) as well as the freedom to enjoy other activities, including cultural and political participation and social well-being (Jackson 2009, pp. 100-102; Spillemaekers et al. 2011, p. 77). Since the HDC approach recognizes these components as essential to people's quality of life, a sustainability strategy involving functioning constraints would not be inconsistent with the focus on expanding people's freedoms, that is, if the concept is qualified.

\section{Conclusion}

We endorse the 2011 HDR's focus on the integral links between equity and sustainability, which is explicitly based on the universality of life claims. These elements are essential for a convincing account of SHD, but the 2011 HDR somewhat overemphasizes human development at the cost of sustainability. Even though it criticizes the paradigm that identifies development with economic growth for being neither sustainable nor equitable, income remains a prominent dimension of development in the 2011 HDR, even beyond what might be called a decent standard of living. However, since rising GHG emission rates are associated with material progress, climate change challenges the definition of human development as the expansion of people's freedoms simpliciter. SHD cannot ignore the unsustainability of the material wealth of the global consumption elites, certainly not when it is elevated to a key part of the development goal.

We have argued that the HDC approach would benefit from unambiguously incorporating the interconnectedness of people and human dependence on the natural environment: whereas the HDC approach might be susceptible of endorsing the expansion of freedoms ad libitum, the account we advocate envisages a more modest development path. Our proposal starts from the view of capabilities as triadic relations between an agent, constraints, and possible functionings. This view suggests that the goal of development includes enhancing people's 
capabilities up to the threshold level as well as functioning constraints preventing people from imposing illegitimately harmful barriers to other people's lives.

Since people's capabilities and well-being are dependent on the environment, unmitigated climate change clearly violates intertemporal justice. Expressed in the triadic syntax, the universality of life claims at least requires ensuring that future people are free from constraints imposed by the adverse effects of unmitigated anthropogenic climate change to enable them to live a worthwhile life. This entails a strong moral reason for not transgressing the biophysical constraints of the ecosphere.

On this basis, we have argued that the goals of SHD should be constructed in accordance with a framework consisting of capability thresholds and functioning constraints. As regards social justice, the goal of SHD should be to secure the capability thresholds for every person in an ecologically optimal way, emitting as little GHGs as possible. Moreover, building upon the existing literature about capability ceilings, environmental sustainability compels us to constrain people's functionings beyond the threshold, in terms of their total net GHG emissions.

In sum, we have proposed to interpret the goals of SHD more modestly than the expansion of freedoms ad libitum, especially concerning material freedoms: when material conditions are secured sufficiently, the focus of SHD should shift to expanding people's social freedoms as well as situating well-being within the biophysical constraints of the ecosphere.

\section{Notes}

1. Environmental sustainability is informed by a scientific account regarding the identification and quantification of the biophysical constraints of the ecosphere (Ross 2009, p. 45). Admittedly, these issues are still subjects of scientific debate, and might ultimately depend on political agreement. Yet, it should be emphasized that there is a substantial body of scientific evidence and a broad consensus regarding the existence of the biophysical constraints of the ecosphere

2. Humanity has by now committed itself to a rise in global temperatures of at least $0.76^{\circ} \mathrm{C}$, and substantial human costs can already be attributed to the resulting climate change (Costello et al. 2009, pp. 1698, 1700-1701). Moreover, the climate will continue to change for the foreseeable future due to the accumulated GHGs and the inertia of the climate system, as a result of which the effect of even the most stringent emissions reduction will take several decades to become apparent as well (Füssel 2007, p. 266). Hence, an equitable climate regime should also comprise adaptation and compensation measures. Nonetheless, our focus in this paper is only on the relevance of mitigation to SHD, since it is 
vital in order not to exacerbate the adverse effects climate change will have on future people and to reduce the root cause of the problem (see also section 3.2 and Füssel 2007, p. 265).

3. The climate change mitigation agenda merely focuses on one aspect of the Earth's ecosystem - the effect of increased GHG emissions on the climate - and this may not reflect environmental sustainability in relation to other aspects of the ecosphere (Ross 2009, p. 44). Together with issues of justice towards the environment (as addressed, for example, in biocentrist and ecocentric theories), these aspects fall beyond the scope of this paper.

4. Although their development has diverged somewhat throughout the years, the Capability Approach has provided the theoretical foundations of the Human Development Paradigm (Robeyns 2005, p. 94). For clarity, we use one denominator to capture their commonalities.

5. The 2011 HDR provides data on a range of indicators of environmental sustainability (e.g. ecological footprint, $\mathrm{CO}_{2}$ emissions and biodiversity), but does not change the HDI computation, so as to keep it as focused as possible (Morse 2003, p. 192; UNDP 1994, p. 91).

6. Since humanity has already committed itself to substantial global warming, it would be utopian to claim that future people can possibly be free from the adverse impacts of anthropogenic climate change. Nonetheless, it is clear that future people should at least be free from the adverse effects of exacerbated climate change (exacerbated or unmitigated being key here; see also footnote 2).

\section{References}

Allen, M. et al. (2009) 'The exit strategy', Nature Reports Climate Change, 3, pp. 56-58.

Anand, S. and Sen, A. (1994) 'Sustainable human development: Concepts and priorities', Occasional paper for the 1994 HDR, [http://hdr.undp.org/en/reports/global/hdr1994/papers/ANAND,\%20Sudhir\%20-

\%20Sustainable\%20Human\%20Development-\%20Concepts\%20and\%20Priorities.pdf], accessed 25 April 2012.

Berlin, I. (1969) 'Two concepts of liberty', [First published in 1958], in I. Berlin, Four essays on liberty, Oxford University Press, Oxford, pp. 118-172.

Byers, H. et al. (2005) Meeting the climate change: Recommendations of the International Climate Change Task Force, The Institute for Public Policy Research, London.

Crabtree, R. (2010) 'Sustainable development, capabilities and the missing case of mental health', in K. Aagaard

Nielsen, B. Elling, M. Figueroa and E. Jelsøe (Eds), A new agenda for sustainability, Sage, London, pp. 159176.

Costello, A. et al. (2009) 'Managing the health effects of climate change', The Lancet, 373, pp. 1693-1733.

Deneulin, S. (2002) 'Perfectionism, paternalism and liberalism in Sen and Nussbaum's capability approach', Review of political economy, 14(4), pp. 497-518. 
Füssel, H.-M. (2007) 'Adaptation planning for climate change: Concepts, assessment approaches, and key lessons', Sustainability Science, 2(2), pp. 265-275.

Gardiner, S. M. (2004) 'Ethics and global climate change', Ethics, 114(3), pp. 555-600.

Hayward, T. (2007) 'Human rights versus emissions rights: Climate justice and the equitable distribution of ecological space', Ethics and International Affairs, 21(4), pp. 431-450.

Holland, B. (2008a) 'Justice and the environment in Nussbaum's "capabilities approach": Why sustainable ecological capacity is a meta-capability', Political research quarterly, 61(2), pp. 319-332.

Holland, B. (2008b) 'Ecology and the limits of justice: Establishing capability ceilings in Nussbaum's capabilities approach', Journal of human development, 9(3), pp. 401-425.

Jackson, T. (2009) Prosperity without growth: Economics for a finite planet, Earthscan, London.

Jamieson, D. (1992) 'Ethics, public policy, and global warming', Science, Technology \& Human Values, 17(2), pp. 139-153.

Leßmann, O. (2011) 'Sustainability as a challenge to the capability approach', in F. Rauschmayer, I. Omann and J. Frühmann (Eds), Sustainable development: Capabilities, needs, and well-being, Routledge, London, pp. 4361.

MacCallum, G. (1967) 'Negative and positive freedom', The Philosophical Review, 76(3), pp. 312-334.

Meadows, D., Meadows, D., Randers, J. and Behrens III, W. (1972) The limits to growth: A report for the Club of Rome's project on the predicament of mankind, Universe Books, New York.

Mill, J. S. (2008) 'On liberty’ [First published in 1859], in J. S. Mill, On liberty and Utilitarianism, Bantam, New York, pp. 1-149.

Miller, D. (1983) ‘Constraints on freedom’, Ethics, 94(1), pp. 66-86.

Mont, O. and Plepys, A. (2008). 'Sustainable consumption progress: Should we be proud or alarmed?', Journal of Cleaner Production, 16, pp. 531-537.

Morse, S. (2003) 'Greening the United Nations’ Human Development Index?', Sustainable development, 11, pp. 183-198. 
Neumayer, E. (2010) 'Human development and sustainability', Human Development Research Paper for the 2010 HDR, [http://hdr.undp.org/en/reports/global/hdr2010/papers/ HDRP_2010_05.pdf], accessed 20 April 2012.

Nussbaum, M. (2000) Women and human development: The capabilities approach, Cambridge University Press, New York.

Nussbaum, M. (2006) Frontiers of justice: Disability, nationality, species membership, The Belknap Press of Harvard University Press, Cambridge.

Nussbaum, M. (2011) Creating capabilities: The human development approach, The Belknap Press of Harvard University Press, Cambridge.

Peeters, W. (2011) 'Integrating the capabilities approach and the ecological space paradigm to address issues regarding global as well as intertemporal justice', Paper presented at the 2011 Annual HDCA Conference, The Hague, 5-8 September.

Peters, G., Minx, J., Weber, C. and Edenhofer, O. (2011) 'Growth in emission transfers via international trade from 1990 to 2008', PNAS, 108(21), pp. 8903-8908.

Rauschmayer, F., Omann, I. and Frühmann, J. (2011) 'Needs, capabilities and quality of life: Refocusing sustainable development', in: F. Rauschmayer, I. Omann and J. Frühmann (Eds), Sustainable development: Capabilities, needs, and well-being, Routledge, London, pp. 1-24.

Robeyns, I. (2005) 'The capability approach: A theoretical survey', Journal of Human Development, 6(1), pp. $93-114$.

Rockström, J. et al. (2009), ‘A safe operating space for humanity’, Nature, 461, pp. 472-475.

Ross, A. (2009) 'Modern interpretations of sustainable development', Journal of Law and Society, 36(1), pp. 3254.

Sachs, W. and Santarius, T. (Eds) (2007) Fair future: Resource conflicts, security and global justice, Zed Books, London.

Sen, A. (1985) 'Well-being, agency and freedom: The Dewey-lectures 1984', Journal of philosophy, 82(4), pp. 169-221.

Sen, A. (1988) 'Freedom of choice: Concept and content', European economic review, 32, pp. 269-294. 
Sen, A. (1990) 'Justice: Means versus freedoms', Philosophy and public affairs, 19(2), pp. 111-121.

Sen, A. (1999) Development as freedom, Alfred A. Knopf, New York.

Sen, A. (2006) 'What do we want from a theory of justice?' The Journal of Philosophy, 103(5), pp. 215-238.

Sen, A. (2008) 'The idea of justice', Journal of Human Development, 9(3), pp. 331-342.

Sen, A. (2009) The idea of justice, Alan Lane, London.

Sen, A. (2010) 'Sustainable development and our responsibilities', Notizie di Politeia, 26(98), pp. 129-137.

Shue, H. (1993) 'Subsistence emissions and luxury emissions’ Law and policy, 15(1), pp. 39-59.

Shue, H. (2011) 'Human rights, climate change, and the trillionth ton', in: D. Arnold (ed), The ethics of global climate change, Cambridge University Press, Cambridge, pp. 292-314.

Spillemaekers, S., Van Ootegem, L. and Westerhof, G. (2011) 'From individual well-being to sustainable development: A path where psychologists and economists meet', in: F. Rauschmayer, I. Omann and J. Frühmann (Eds), Sustainable development: Capabilities, needs, and well-being, Routledge, London, pp. 62-82.

UNDP (1990) Human Development Report 1990, Oxford University Press, Oxford, [http://hdr.undp.org/en/reports/global/hdr1990/chapters/], accessed 25 April 2012.

UNDP (1994) Human Development Report 1994: New dimensions of human security, Oxford University Press, Oxford, [http://hdr.undp.org/en/reports/global/hdr1994/], accessed 25 April 2012.

UNDP (1998) Human Development Report 1998: Consumption for human development, Oxford University Press, Oxford, [http://hdr.undp.org/en/reports/global/ hdr1998/], accessed 25 April 2012.

UNDP (2000) Human Development Report 2000: Human Rights and human development, Oxford University Press, Oxford, [http://hdr.undp.org/en/media/HDR_2000_EN.pdf], accessed 25 April 2012.

UNDP (2007) Human Development Report 2007/2008: Fighting climate change: Human solidarity in a divided world, Palgrave MacMillan, Basingstoke, [http://hdr.undp.org/en/media/HDR_20072008_EN_Complete.pdf], accessed 25 April 2012.

UNDP (2010) Human Development Report 2010: The real wealth of nations: Pathways to human development, Palgrave MacMillan, Basingstoke, [http://hdr.undp.org/en/media/HDR_2010_EN_Complete_reprint.pdf], accessed 25 April 2012. 
UNDP (2011) Human development report 2011: Sustainability and equity: A better future for al, Palgrave MacMillan, Basingstoke, [http://hdr.undp.org/en/media/HDR_2011_EN_Complete.pdf], accessed 25 April 2012.

Vanderheiden, S. (2008) Atmospheric justice: A political theory of climate change, Oxford University Press, Oxford. 